\title{
Lionel Obadia, Shalom Bouddha. Judaïsme et bouddhisme, une rencontre inattendue
}

Paris, Berg International, 2015, 152 p.

\section{Mira Niculescu}

\section{(2) OpenEdition}

\section{Journals}

Édition électronique

URL : http://journals.openedition.org/assr/27422

DOI : $10.4000 /$ assr. 27422

ISSN : $1777-5825$

Éditeur

Éditions de l'EHESS

Édition imprimée

Date de publication : 1 octobre 2015

Pagination : 342

ISBN : 978-2-7132-2515-4

ISSN : 0335-5985

Référence électronique

Mira Niculescu, « Lionel Obadia, Shalom Bouddha. Judaïsme et bouddhisme, une rencontre inattendue ", Archives de sciences sociales des religions [En ligne], 172 I octobre-décembre, mis en ligne le 08 juin 2016, consulté le 24 septembre 2020. URL : http://journals.openedition.org/assr/27422 ; DOI : https:// doi.org/10.4000/assr.27422

Ce document a été généré automatiquement le 24 septembre 2020.

(c) Archives de sciences sociales des religions 


\section{Lionel Obadia, Shalom Bouddha. Judaïsme et bouddhisme, une rencontre inattendue}

Paris, Berg International, 2015, 152 p.

Mira Niculescu

\section{RÉFÉRENCE}

Lionel Obadia, Shalom Bouddha. Judaïsme et bouddhisme, une rencontre inattendue, Paris, Berg International, 2015, $152 \mathrm{p}$. 
Enfin un ouvrage universitaire sur les Juifs bouddhistes! Aux États-Unis, dans les années soixante, l'engagement de baby-boomers d'origine juive dans le bouddhisme a été tellement remarqué que l'on a commencé à parler des «Juifsbouddhistes » comme d'une nouvelle figure à trait d'union. Ce phénomène de la contre-culture devient connu du grand public avec la publication en 1991 du bestseller américain Le Juif dans le Lotus, un récit relatant le voyage d'une délégation de rabbins américains à la rencontre du Dalaï-lama. C'est à partir de cet ouvrage qu'est popularisée l'expression «jubu» comme contraction de "Jewish Buddhist", un terme au départ ironique et à la pertinence controversée, terme que choisit de reprendre Lionel Obadia pour désigner dans son ouvrage ceux qui « conjuguent un héritage juif et un engagement bouddhiste ».

Depuis les années 1990, la figure de Juif bouddhiste fait l'objet d'un engouement médiatique - comme en atteste le nombre d'autobiographies, articles de presse et internet écrits sur le sujet. Par contraste, peu de travaux universitaires ont été dédiés à ce phénomène, et il s'agit surtout d'articles ou de chapitres d'ouvrages collectifs (Vallely au Canada, 2008 ; Loss en Israël, 2010 ; Gez en Angleterre, 2011 ; Ariel aux ÉtatsUnis en 2012 ; et Niculescu en France, 2014). Après Torah and Dharma (Linzer 1996), Shalom Bouddha est seulement la seconde monographie à se focaliser sur le sujet. Une telle pénurie académique peut être attribuée en grande partie à la difficulté à saisir l'objet: les "Juifs bouddhistes " sont non seulement malaisés à identifier et à dénombrer, ils présentent également, comme le rappelle à juste titre obadia, des postures individuelles à la fois uniques et fluctuantes : délicates, donc, tant à définir qu'à saisir.

C'est pourquoi l'on ne peut que saluer la démarche de l'anthropologue français de se pencher sur le sujet. Un sujet qui l'avait interpellé au cours de ses recherches sur le bouddhisme en France et sur le chamanisme en Asie, lorsqu'il avait été frappé par la présence récurrente d'individus d'origine juive parmi ceux qu'il appelle les " convertis ». Après avoir abordé dans une série d'articles les questions de la double posture de Juif et de bouddhiste (2007), de la rencontre entre judaïsme et bouddhisme (2008), et du bouddhisme en Israël (2012), Lionel Obadia consacre avec Shalom Bouddha une courte monographie à cette « rencontre inattendue ».

Dans cet ouvrage, à la réflexion théorique, notamment sur les concepts qui y sont mobilisés tels que "conversion», « religion», "bricolage », « syncrétisme » ou "modernité », a été préférée la description empirique : Shalom Bouddha se focalise sur une série d'impressions et de réflexions de terrain rassemblées pour offrir une vue d'ensemble du phénomène. Après avoir fait état du peu de chiffres disponibles sur le phénomène - les Juifs engagés dans le bouddhisme représenteraient de 6 à $30 \%$ des 
bouddhistes occidentaux; après avoir dressé une "brève sociologie des jubus » - à l'image des bouddhistes occidentaux, ils viendraient de classes supérieures éduquées ; et après avoir resitué la «rencontre interreligieuse » entre judaïsme et bouddhisme dans une « histoire longue » qu'il fait remonter à l'Antiquité pour aboutir dans l'Israël contemporain, Obadia brosse à grands traits un portrait idéal typique des « jubus ».

Il se sert, pour ce faire, de deux sources de terrain : la « cohorte anonyme » d'individus juifs rencontrés dans des milieux bouddhistes, et - surtout - des ouvrages autobiographiques de Juifs "bouddhistes », notamment trois d'entre eux, qui relatent respectivement les itinéraires spirituels d'une enseignante bouddhiste Vipassana (Sylvia Boorstein), d'un rabbin massorti (Alan Lew), et d'une enseignante de kabbalah formée au bouddhisme zen (Karen Cobrin-Cohen). La diversité de ces trois profils réunis sous la même étiquette témoigne de la définition large adoptée par l'anthropologue pour parler « des jubus » comme d'un groupe social à part entière, bien qu'il note justement ailleurs qu'il s'agit d'une « catégorie linguistique » sans corrélation systématique avec les réalités vécues.

6 Afin de comprendre la figure de Juif bouddhiste, Obadia énumère une série de raisons explicatives : aux délaissements du judaïsme à la faveur d'engagements individuels dans le bouddhisme d'abord; aux retours souvent constatés au judaïsme ensuite; et aux variations culturelles de ce phénomène aux États-Unis, en Israël et en France enfin.

Dans un second temps, reprenant la typologie proposée dans l'un de ses précédents articles (2007), il identifie trois modèles de «jubus»: ceux qui opèrent une «différenciation horizontale» entre «le judaïsme comme culture et le bouddhisme comme spiritualité »; ceux qui opèrent une "différenciation verticale » entre ces traditions au sein de leur propre trajectoire croyante (la fameuse image des « racines juives et des pétales bouddhistes "); et ceux qui opèrent une "synthèse " sous la forme de «bricolages particuliers». Cependant, précise-t-il, «le statut de jubu correspond moins à un état stabilisé qu'à un mouvement d'oscillation pendulaire et perpétuel». C'est pourquoi, considérant que finalement, «la question centrale de l'identité des jubus" est "celle de leur localisation", il identifie trois types de dynamiques: le "détour» pour mieux revenir; le «départ définitif» sous la forme d'une "pleine conversion » au bouddhisme; et la " combinaison", sous forme soit de "cohabitation confessionnelle » ou "syncrétisme », soit de «fusion identitaire ». D'après ce dernier modèle, la figure de Juif bouddhiste, qui selon Obadia est «plus que du bricolage et moins que du syncrétisme » se déclinerait donc dans sa forme aboutie, ou bien comme une figure de double « religion », ou bien comme une double "identité ».

En démontrant l'intérêt d'explorer le phénomène des "Juifs bouddhistes", Shalom Bouddha confirme la nécessité pour le sociologue du religieux soucieux de comprendre les effets sur les religions historiques de la globalisation du religieux, de se pencher sur un tel phénomène. 